\title{
Can Web 2.0 applications save e-democracy? A study of how new internet applications may enhance citizen participation in the political process online
}

\author{
Yana Breindl* and Pascal Francq \\ Department of Information and Communication Sciences, \\ Université Libre de Bruxelles, Avenue F.D. Roosevelt, \\ 50 - CP123, B-1150 Brussels, Belgium \\ E-mail: ybreindl@ulb.ac.be \\ E-mail: pfrancq@ulb.ac.be \\ ${ }^{*}$ Corresponding author
}

\begin{abstract}
Increased citizen participation is a core element of both Web 2.0 applications and the concept(s) of e-democracy. This paper proposes a prospective view of how the Web 2.0 can be used in the context of e-democracy. After a review of both concepts, the main perceptions of internet users concerning their political activity on the internet are highlighted by an online survey realised in January-March 2007. Various Web 2.0 applications are then discussed in the light of VEDELs axis - information, discussion and decision-making - in order to identify how they may enhance the implication of citizens in the political process through the internet.
\end{abstract}

Keywords: e-democracy; Web 2.0; emerging applications; participation; social bookmarking; e-participation; politics; democracy; information and communication technologies; internet; survey.

Reference to this paper should be made as follows: Breindl, Y. and Francq, P. (2008) 'Can Web 2.0 applications save e-democracy? A study of how new internet applications may enhance citizen participation in the political process online', Int. J. Electronic Democracy, Vol. 1, No. 1, pp.14-31.

\begin{abstract}
Biographical notes: Yana Breindl is a Doctoral student in the Department of Journalism, Information and Communication Sciences at the Université Libre de Bruxelles (ULB), Belgium. At present, she focuses on her Doctoral Dissertation that discusses the social and political implications of Information and Communication Technologies (ICT) used by citizens in order to influence the political process. Her main research interests are e-participation, citizen involvement and empowerment, e-democracy, virtual communities, social media networking and e-mobilisation and activism.

Pascal Francq earned his Master's Degree in applied Science at the Université Libre de Bruxelles (ULB) in 1996, his PhD in 2003 after a two-year experience at a private company. From 2004 to 2008, he was a Professor at the ULB, holding the Digital Information Chair. He was the main contributor of the open source platform GALILEI. Currently, he works as a researcher on the internet, its technologies and its impacts. He focuses particularly on the use of genetic algorithms in the context of search engines and clustering technologies.
\end{abstract}




\section{Introduction}

Since the beginning of computer science, many authors have argued that data processors may help to build a better world (Wiener, 1965). Information and Communication Technologies (ICT) such as the internet are seen by many people as the realisation of the 'global village' prophesied by McLuhan (1962) in the 1960s: a world where all individuals are interconnected and can take active part in common processes.

However, McLuhan's vision has not come true. Many individuals remain excluded and isolated from global interconnection. An increasing number of citizens asks nevertheless for greater participation in the political process as many Western democracies face a legitimation crisis. The hope that the internet may respond to those citizen needs is often expressed. Additionally, the emergence of the concept of the Web 2.0 has transformed the image of the World Wide Web: from a medium mainly used by specialists it is now perceived as a virtual place where democracy among internet users is a reality.

This paper argues that some Web 2.0 applications, despite several well-founded criticises, are useful in the context of e-democracy. In the following sections, the authors propose therefore a prospective view of how some Web 2.0 applications reply to e-democratic needs expressed by internet users. Concretely, Section 2 delineates the concept(s) of e-democracy, examining it through three dimensions: information, discussion and decision-making while Section 3 focuses on the concept of Web 2.0 and its main applications. Section 4 discusses the results of an online survey, highlighting the main perceptions that people have about e-democracy. Section 5 argues that Web 2.0 applications can be used to respond to the issues related to these perceptions. Finally, Section 6 summarises the key results of this paper.

\section{E-democracy}

E-democracy can be deemed as the use of ICT, above all the internet, in the policy-making process and the State-citizen relations in order to encourage a direct and more active citizen participation in public life and the decision-making process. Other terms generally employed to refer to e-democracy are electronic democracy and online or digital democracy, also encountered are teledemocracy and cyberdemocracy. This paper refers mainly to the first two expressions.

First of all, a clear distinction has to be made between e-government and e-democracy, though they are linked. E-government is the use of ICT in order to inform, canvass and increase the participation of citizens in the governance of public affairs throughout the political process (Prevost, 2003). While e-government and e-administration refer to online public or administrative tasks, e-democracy more generally concerns the political use of the network by citizens. In other words, e-government evokes top-down practices while e-democracy refers to bottom-up activities. The first puts the stress on governmental action while the latter emphasises citizen's online participation in political action. As both practices are connected, e-government alone cannot lead to a reinforcement of democracy (Sclove, 2003).

In its essence, democracy signifies that the state sovereignty belongs to the people. Direct democracy is considered as the political ideal of 'pure', Athenian inspired 
democracy. ${ }^{1}$ However, in our complex societies, representative democracy is the most widespread political system as direct decision-making seems practically impossible to realise. "There is no such thing as democracy", writes Barber (2000). "There are only a variety of forms of governments, which have a variety of characteristics that can be labelled under different groupings that define (not without controversy) distinctive forms of democracy" (Barber, 2000). Indeed, various forms of democracy exist and no clear definition has yet emerged for an electronically renewed democracy.

When considering e-democracy, a tension between the advocates of a more direct, plebiscitarian democracy and the supporters of a deliberative or participatory system re-emerges (Maigret, 2000). The first ones believe that the advent of the internet is synonymous to the transformation of our political systems into a direct democracy where all citizens decide what is best for them. The latter consider that representation cannot be abolished but that citizen participation has to be encouraged in a technically supported process of discussion and decision-making.

The democratic potentials of the network, such as interactivity, increased availability of (political) information and more efficient and decentralised user control reinforce the internet as an interaction platform for citizens who wish to contribute to the political process. The crisis of representative democracies in the Western world makes the question of reforming democracy by using new technologies a central issue of e-democracy. Early supporters announced a revolution, a total shift of society after the spreading of the internet (Rheingold, 2000; Becker and Slaton, 2000; Levy, 2002), the accomplishment of the 'global village' prophesied by McLuhan (1962); A world of free expression, unbound, where humanistic ideals such as freedom and fraternity would reign.

Political participation is at the centre of e-democracy. It can be defined as the sum of acts realised by individuals or groups in order to influence the way the political system operates (Hagen, 1997). The famous quote by Abraham Lincoln defining democracy as "the government of the people, by the people and for the people" already insists on the central importance of citizen participation in democracy. As 'traditional' participation tends to diminish in many modern democracies (e.g., voting, political interest, etc.), the hope that the internet can reverse that movement is expressed by many voices. In practice, many citizens show indeed a reduced interest for political affairs though they admit that it would be desirable to participate more actively. For instance $41 \%$ of all Europeans (Europe 25) assure that they are not interested in the political life of their state (European Commission, 2006). Consequently, many authors hope that the internet will renew democratic systems.

It is not the first time Utopian discourse surrounds the emergence of a new type of media. The arrival of the radio in the 1920s, then of the television in the 1960s has raised similar hopes (Lappin, 1995). Both media were credited high democratic potential as has been the internet in the 1990s. Each time these hopes have vanished with the further commercialisation of the media, citizens remaining passive users. Why would things be different with the internet?

Interactivity is what distinguishes the most the internet from other media such as radio or television. Even digital or cable television, considered as interactive in the 1980s, cannot compete with the new media. Yildiz (2002) speaks of a "new communication model on the internet" as users are not subject to the information they receive but can actively construct the content they wish to receive or diffuse. This communication is 
'multidimensional' (Yildiz, 2002), the internet being used to inform oneself but also to communicate to one or more persons without limits of time or space.

Early discourse surrounding e-democracy was divided: many authors approached the phenomenon in a highly 'utopian' way; many others chose a rather 'dystopian' perspective. For the first, the internet is seen as accomplishing direct democracy, freedom and brotherhood in a world gone online (Levy, 2002; Rheingold, 2000). For the latter, the 'informatisation' of society will inevitably lead to an Orwellian state, where an efficient technocracy spies out citizens deprived of fundamental rights (van de Donk et al., 1995).

Beyond these extremes, different models have been proposed by researchers in order to theorise e-democracy. Among them are the models of Edwards (2004), Hoff et al. (2000) or Hacker and Van Dijk (2001) which consider e-democracy as a whole theoretical entity. However, e-democracy does not exist yet; only attempts and experiments trying to realise that online political system. Therefore the authors prefer to distinguish different forms of political actions on the internet. In order to do so, this paper refers to the three axes underlined by Vedel (2003) in his studies over e-democracy: information, discussion, online decision-making and participation.

\subsection{Information}

One of the characteristics of new media such as the internet is that an exponential amount of information can transit through these networks (Abramson et al., 1988). Thanks to the internet, citizens can easily access political content such as news, opinions, facts and data. Governmental internet sites have nourished across the Web; providing information is generally their main goal (Loiseau, 2003). As many optimists believe, increased access to political information is supposed to extend governmental transparency and thus democracy.

If many people believe access to information is eased by the arrival of the internet, finding the right or exact information can be difficult for any internet user. Though $87 \%$ of internet users state they are satisfied with the results proposed by search engines, only $17 \%$ assure they always find the information they are looking for (Fallows, 2005). More preoccupying: most of them (62\%) are unaware of the distinction between paid and unpaid results while a large majority declares they would stop using search engines if their presentations of the paid results are not clear.

Too much information may also lead to disinformation. Even if information can be freely accessed, few internet users tend to deplete that possibility. Instead of searching always new information, citizens rather try to filter, reduce and administer the overload of information they receive (Vedel, 2003). Unskilled or inexperienced surfers are likely to misuse search engines and can more easily be deceived by (dis)informative content.

Furthermore, many internet sites ignore the interactive possibilities of the network and tend to supply unidirectional information. Internet users are often perceived as customers of public services and not as citizens willing to gain influence in the political process (Constant, 2002). Information alone does not yet lead to increase citizen participation. 


\subsection{Discussion}

Discussion is a point that has caught large attention in the study of political activity on the internet. For many optimists, the cyberspace constitutes a new public sphere where exchanges transcend geographical, social and cultural boundaries; a place, without central control, where any individual is free to express his opinions and thoughts. The new public sphere is organised following the principles of rationality, accessibility and transparency emphasised by Habermas (1991). Online political discussion takes place in forums or discussion groups and, more recently, in blogs and vlogs or online chats with politicians. Though much is said on the internet, clear influence on political decision-making is not yet following.

Initially the internet was perceived as a platform where unbound speech could unfold, making 'distorting' intermediaries such as journalists, publishers or producers redundant. However, boundaries remain while new ones appear. "The internet is no neutral zone of citizen activity" comments Sassi (2000). Moderation appears spontaneously to frame forums and groups. New opinion leaders emerge as well. Even though traditional media may loose its exclusive position as a main gatekeeper, it has to confront itself with new intermediaries. This phenomenon is what Edwards (2004) identifies as 're-intermediation'. The main problem posed by the internet concerns therefore their legitimisation not their disappearance (Wolton, 2000).

Furthermore, there remains a tendency to privilege mainstream thinking on the internet. Alternative or new sites have difficulties to compete with already installed ones or sites that dispose of important resources. As the ranking of many search engines such as Google privileges sites where many links point to, new companies have emerged, proposing to optimise Internet sites in order to influence this ranking. This approach is also known as Search Engine Optimization (SEO). Additionally, English and Western sites prevail, deepening the digital divide and hardening access for persons from other cultures.

In the past, each time a new support for free discussion emerged, totalitarian authorities tried to control what was said and who was participating online. As for traditional media, censorship has also appeared online in cyberspace as, for example, in China or, more recently, in Myanmar. Free speech is far from being ensured in cyberspace.

\subsection{Decision-making and participation}

The third axis highlighted by Vedel concerns online decision making and participation. This point focuses on the way citizens are able to participate more actively in the political process, not only by discussion, but by having an impact on the final decision. Examples include online consultations, opinion polling and surveys and referenda or electronic voting. However, few democracies experiment this kind of online practices. Electronic voting is by far the most media covered initiative but also one of the more controversial online practices.

The impact of cybercitizens remains nevertheless highly uncertain. Do politicians really listen to online claims? Rare are the examples of e-petitions or online consultations that have led to concrete changes in the political agenda. 
Many politicians tend to ignore what happens on the Web or consider the internet users as consumers and not as citizens in an egalitarian discourse (Constant, 2002).

Even if an impact could be proved, e-citizens are hardly representative of the larger group constituting society. Active minorities such as alternative or extremist groups are over represented (Corbineau and Barchechath, 2003). Traditional gatekeepers - one might think about famous journalist-bloggers - are more influential than unknown internet users.

Beyond these considerations, the concept(s) of e-democracy is mainly related to the use of the internet to increase citizen participation (see above). Consequently, any element - such as technology, behaviour, content, etc. - enhancing political participation should facilitate e-democratic processes. Recently, the concept of the Web 2.0 has emerged, emphasising new ways for internet users to contribute to the content of the internet. Many parallels can be drawn between the concept(s) of e-democracy and the Web 2.0 as we will see in Section 3.

\section{The Web 2.0}

Appearing in the early 2000s, the Web 2.0 has several definitions depending on the authors, including:

- a set of technologies increasing the interaction of Websites (in particular AJAX)

- a synonym for the Semantic Web

- a collaborative vision of the Web.

Endless debates about a complete definition of the concept of the Web 2.0 can be hold. However, in the context of e-democracy, the authors retain the latest definition, in other words the idea that everybody can contribute to the production of content on the internet.

The role of internet surfers dramatically changes: from a 'passive consumer of information', users become active organisers of online content. Indeed, more and more individuals or groups choose to post their favourite music, text or video online, sharing their messages on interactive and/or collaborative sites. As a consequence, the internet content becomes more decentralised than ever before. In fact, the decentralised structure of the internet is based on the centralisation of information by a limited number of commercial data centres. This facilitates the potential control of internet users' information. In fact, decentralisation and participation are clearly similar to both e-democracy and Web 2.0. Not surprisingly, hopes emerge that the latter might reinforce the former.

Some authors argue that participation of internet users in the production of internet content is far from new. Several commentators present the concept of Web 2.0 more as a buzz-word than as a real revolution. However, the massive increase of Web surfers in recent years is changing the dynamic of the internet. 'Web 2.0' describes therefore principally the period characterised by an easiness in content production and publication on the internet.

As for the concept(s) of e-democracy (Section 2), a continuous tension between an utopian vision and a pessimistic view surrounds the Web 2.0: some consider the Web 2.0 as a form of democratic management of the internet, others see it as a place where popularity and quantity replace quality. However, critics and supporters both agree 
that the Web 2.0 constitutes a new phenomenon whose exact impact cannot yet be determined. In the following subsections, new Web 2.0 applications are examined among which blogs and wikis, social bookmarking and networking sites.

\subsection{Blogs and Wikis}

Blogs and Wikipedia are the best known examples of Web 2.0 applications, as well for the defenders as for the opponents of the Web 2.0.

Blogs (or Weblogs) are websites where any internet user may publish whatever content he or she wishes to share (Blood, 2002). In many blogs, authors share their daily experiences in life, just as they would do in a diary. Yet, as already mentioned in Section 2.2, some blogs are more specific, as shows the increasing number of blogs with political content. Since most blogs give the opportunity to Web surfers to comment on a given entry, they are also virtual places where different subjects can be discussed. Most blog authors add many hyperlinks on their site, referring to other blogs which discuss the same kind of subjects. This creates a galaxy of blogs related to a given domain. As some search engines ${ }^{2}$ are specialised in retrieving information from blogs, the accessibility of everyones opinion is increased. Many authors, such as Gillmor (2006), claim that these blogs represent a new media available to citizens to inform their fellow internet users without any form of censorship. Consequently, blogs are often perceived as the 'killer application' for e-democracy: a core phenomenon that supports the larger emancipation of mankind on the internet. The way bloggers informed the world community about oppression in Myanmar in autumn 2007 is just one example of how blogs can contribute to the political debate. On the contrary, opponents claim that, since everybody can publish any 'information' online, the internet will be more and more polluted with thrash, leading to misinformation handicaping the democratic process.

Wikis are websites where internet users can build collaborative manuals and/or encyclopedias. Founded in 2001 , Wikipedia $^{3}$ is the most frequently cited and best known wiki. It is a free content online encyclopedia project written in several languages by internet users. The basic idea behind the project is that any Web surfer can contribute to create the collaborative content; the community of writers playing the role of editor to ensure a certain quality of the final content. When it comes to defend this collaborative form of content production, a comparison between Wikipedia and the reference work Encyclopedia Britannica, published in the international journal Nature in 2005 and concluding that Wikipedia may be a reliable source of information, is often cited (Giles, 2005). Wikipedia contains already a large number of politically-oriented entries and a portal called 'Political Ideologies'. Nevertheless, Wikipedia is regularly criticised because of its lack of control on who writes what (Schiff, 2006; Waters, 2007). For Keen (2007), a system where the knowledge of an expert - of the corresponding domain - has no more value than the one of any Web surfer leads to the destruction of culture.

\subsection{Social bookmarking applications}

Another kind of applications labelled Web 2.0 are social bookmarking ones such as del.ico.us, Flickr or YouTube. The idea behind these application is to propose a sort of 'human indexing' of the internet: when users find relevant resources on the 
internet - Web pages, pictures or videos - they associate keywords - called tags - that describe, for them, the content of these resources. Web surfers are then able to see all the resources tagged with the same keywords by others.

These applications are based on three hypotheses:

1 people use the same keywords to tag related content

2 if someone tags a resource, the content is supposed to be humanly assessed as relevant

3 it is easier to find useful information based on the assessment of 'normal internet users' on the internet rather than metadata provided by experts using specialised taxonomy in reference databases.

These hypotheses reflect the idea that any internet user can participate in the organisation of knowledge on the internet. This decentralised vision of Web indexing is thus comparable to the idea of e-democracy where, ideally, every citizen contributes to define the political priorities. However, each of these hypotheses may be criticised, in particular the issue concerning the expertise of Web surfers tagging a given resource with a given set of keywords is identical to the critics made to blogs and wikis.

\subsection{Social networking systems}

Social networking systems, such as Facebook or LinkedIn, are used to connect people sharing the same interests or having similar profiles - e.g., a common educational background. To facilitate the creation of new connections, most of these tools propose a system where people may be introduced to others via the intermediary of a common relation. Moreover, some of these applications propose to their users to rate other persons following their reputation and/or the trust they have towards that individual (Chen and Singh, 2001). These systems have proven to be useful to share knowledge between users (Coenen, 2006). Since the concept of e-democracy implies that ICT should facilitate the creation of organised actions, it is clear that social networking systems can be useful in that context.

Yet, there are also limitations to these systems, in particular:

- it is still unclear how reputation emerges in these applications, and in which proportions a relation between the reputation of a user and the quality of the information he or she provides can be determined

- the concept of trust is difficult to define since it is generally possible for users to interact through nicknames.

Indeed, the Web 2.0 evolution of the internet has several drawbacks. Educating the internet users to adopt a critic position towards the information they read is more than ever crucial, in particular because the internet becomes the main information source for an increasing number of people (Shannon, 2007).

This brief review of the concepts of e-democracy and the Web 2.0 shows clear relations between the two phenomena. Both stress the importance of enhancing the role of internet users. As e-democracy wishes to involve increasingly cyber-citizens in the political process, new Web 2.0 applications may contribute to augment the impact of internet users in the democratic system. The following section presents a survey, realised 
in February-March 2007, questioning internet users about their attitudes and perceptions concerning e-democracy.

\section{Survey analysis}

"How do you think and feel about political practices on the internet?" was the central theme of an online questionnaire ${ }^{4}$ to which 946 internet users answered. The online form was chosen in order to obtain information about various people living in different contexts. Our survey is not strictly representative, no online survey can be, in particular on a subject related to the internet. Still, we believe it captures the main tendencies surrounding e-democracy.

Questions were separated in five fields: internet use, perception of democracy, political engagement and participation, perception of e-democracy and personal data about the respondents. The link of the questionnaire was posted on political internet forums and sites; it was sent to the main political parties of Belgium, France and Germany; the URL was also spread by email across the Web. The aim was to obtain answers from politically engaged and less politically engaged internet users. ${ }^{5}$

The main hypotheses can be summed up as follow:

- traditionally engaged citizens are more likely to have a positive opinion about e-democracy

- $\quad$ personal characteristics, internet use and the representation of democracy have an influence on that perception

- obstacles to a larger degree of e-democracy remain important.

In this paper, only the main results of the survey are presented. Interested readers can contact the authors for more details. For the questions examined in this paper, users were asked to give their degree of agreement on a scale ranging from 1 (do not agree) to 5 (totally agree).

\subsection{Internet users}

The sociological profile of the respondents is the following: they constitute a group of young adults (average age $=41$ ), highly educated, generally rather male than female ( $60.5 \%$ of men; $39.5 \%$ of woman), using the internet at home, a great majority living in urban centres and being overwhelmingly native from Western Europe (95.2\%). From the 946 internet users that answered, 53\% chose the French language to do so, 28\% German, 13.4\% Dutch and 5.6\% English. The English speaking population is underrepresented in this survey. The general profile of the respondents corresponds to the one of the average internet user (as far as a profile can be established). A certain representativeness of internet users can indeed be asserted.

As shown in Figure 1, a majority answered that they frequently use the internet to obtain information, to communicate or for leisure purposes. The creation of blogs/vlogs or the participation in collaborative or political sites is far less widespread with few users asserting they are active in that field. 
Figure 1 Internet use

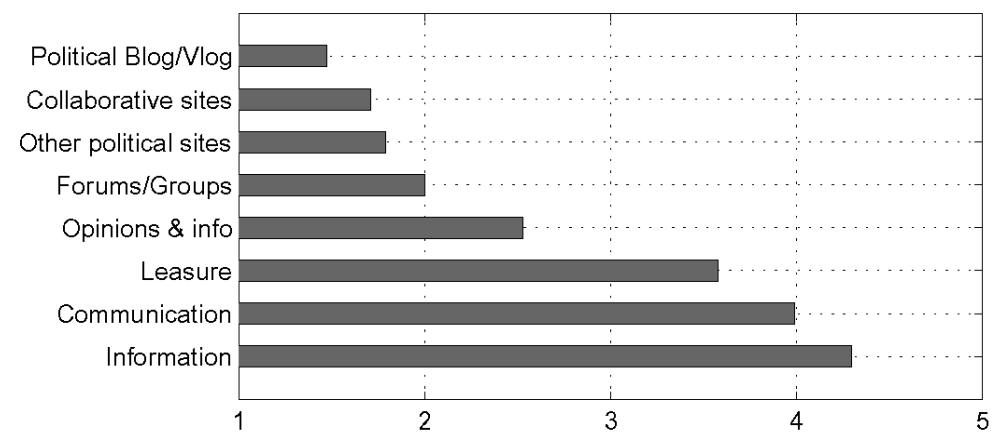

Close to $80 \%$ of the respondents consider that democracy signifies primarily freedom of expression; $72.2 \%$ conceive it as a synonym to citizen participation in the policy-making process and $69.9 \%$ correlate democracy with the respect of fundamental rights (e.g., human rights). While $54 \%$ consider that there is a clear democratic crisis, $70 \%(70.8 \%)$ estimate that political participation is useful.

This attachment to basic democratic values has an impact on the perception the respondents have about the political use of the internet. The network is indeed perceived as a tool that can contribute to improve the political system as many consider democracy to be experimenting important difficulties.

\subsection{Political engagement}

Clear differences appear following the 'traditional' political characteristics of internet users. Offline activities are linked to online practices. "People already engaged in offline political networks use the internet to consolidate their participation", write Calenda and Mosca (2007). "General characteristics of offline participation are reproduced online". These conclusions are confirmed by our survey. People who are more engaged in their offline life are also more positive about using the internet for chatting with politicians, signing e-petitions or participating in political forums or discussion groups.

The people who answered the questionnaire are generally politically engaged. Seventy percent declare that they are interested in politics, $36.9 \%$ are even members of a structure having a political activity. Moreover, only 3.1\% admit that they never vote, yet, except one, they are also devoid of the right to vote which most likely explains their abstention. In total, $91.9 \%$ generally vote in national elections while the participation average in Europe (25) only approaches the 70\% (European Commission, 2006).

Various variables such as the interest in politics, the electoral behaviour or the offline political participation of the respondents have been combined in order to measure the respondents' political engagement (petitions, memberships to political parties, etc.). Two categories emerged. Although the respondents are generally more engaged than the average West European, we have divided them into a group of 'not engaged' people and a group of 'engaged' ones, depending on the score they obtained. Fifty-four percent belong to the group of the 'not engaged persons' while $45.5 \%$ were categorised as 'engaged'. 


\subsection{Main issues}

Beyond the differences concerning the 'traditional' political engagement, most internet users who answered the study have a rather positive opinion about e-democracy. More than $66 \%$ consider that e-democracy is a "tool able to enhance citizen participation". Nearly as much $(62.8 \%)$ believe that the political use of the internet will lead to a modernisation of democracy. Many conceive it is a 'future reality' $(49.4 \%$ whereas only $17.69 \%$ disagree) and only a question of time before its extension throughout the world.

Views differ concerning the shape this online democracy will take. Many respondents are opposed to certain practices such as electronic voting. Others $(47.5 \%)$ believe that online democracy is not more than a formula to reduce state-running costs while increasing the efficiency of public administration. This may signify that there is a certain confusion between 'e-democracy' and 'e-government' for many Web surfers.

To the question "Is the internet (or can it be) useful for...?" respondents answered unanimously that it is very useful for accessing internet services such as administrative forms like tax declarations - maybe because these are the most widespread governmental services online. Obtaining information, filling in e-petitions or following political debates on the internet are also facilitated through the Web whereas direct discussion with politicians or e-elections are less favoured by respondents. As shown in Figure 2, there is a clear difference in the perception of the political utility of the internet in function of the political engagement of users.

'Engaged' people distinctly consider that online practices such as retrieving political information, following discussions on the internet or writing to politicians are useful.

Figure 2 Perceived usefulness

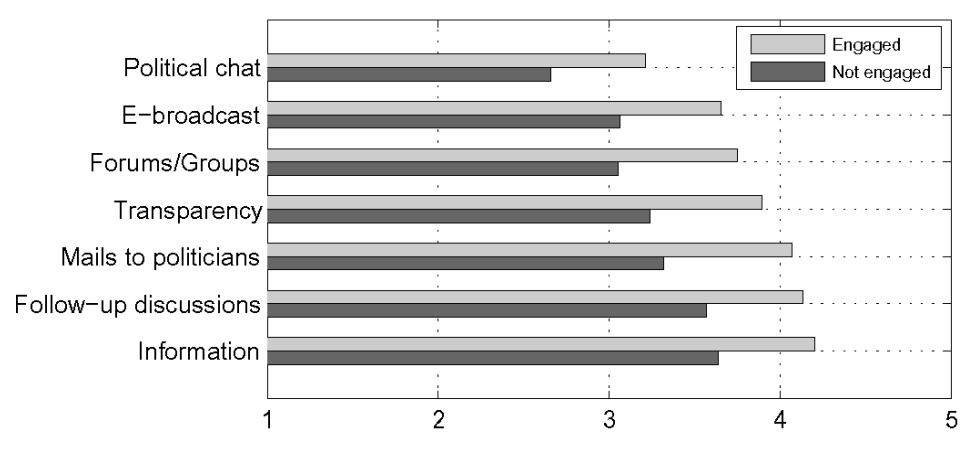

They are far more positive about the political use of the network than 'not engaged' persons. Most 'engaged' persons are clearly interested in e-democracy while a majority of 'not engaged' persons admits they never have heard about the phenomenon before answering the questionnaire (only $37 \%$ of not engaged persons already heard about e-democracy compared to $77 \%$ of 'engaged' persons).

The divergence between the two categories is the most important concerning the variables 'information' and 'discussion' (Figure 2). For engaged people, those two axes are fundamental in an online democracy. However, consultative practices must also find their place in a technically supported democracy. In general, respondents were more positive about practices they knew about or experienced than practices - such as chatting 
with politicians or following political online programs - they never or rarely used the internet for.

If we consider the answers at the light of the distinction between information, discussion and decision-making drawn by Vedel (see Section 2) the following remarks have to be made:

- Besides administrative services, respondents perceive the internet as clearly useful for informative and consultative purposes. This corresponds to the first and the third axes of Vedel: information and decision-making. Indeed consulting the population before taking a political decision can clearly contribute to their implication in the democratic process.

- The second axis - discussion - is generally less favoured by respondents compared to the two other axes. The use of the internet to send emails to politicians, to participate in political forums or discussion groups or to chat with political personalities gathers less approval than activities of the two axes mentioned here above. However, 'engaged' people are far more positive about these axis than 'not engaged' ones as analysed here-above.

Furthermore, the authors found out that not only people you would expect use the most the internet, e.g., young people, are most positive about e-democracy. Also elderly people and lower educated ones wish to use the internet to take part in the political process. Indeed, in our survey, the age, education or origin of respondents does not influence the perception they have about e-democracy. However, this conclusion must be taken carefully as respondents form already a group with a certain homogeneity - the internet users (see Section 4.1).

People also expressed concerns about online voting. This variable clearly divides respondents. It is the only question where 'engaged' and 'not engaged' answered averagely the same. Moreover, many used the free spaces of the questionnaire to contest e-voting.

Respondents remain equally worried about various obstacles such as the digital divide, risks of manipulation and security issues. Both categories obtain similar scores concerning the barriers to a larger diffusion of e-democracy. The exclusion of people who do not have internet access - or do not wish to have - is clearly the most preoccupying obstacle. The lack of citizen engagement and government's resistance to change also worries respondents. Governmental distrust in new technologies appears as a relatively small obstacle. Some respondents even consider that there is too much trust in technology.

The internet is seen as an additional tool to reform democracy, not as a substitute for existing practices. Many respondents distinctly expressed their fear that democracy would turn into an 'online game'. Offline and online practices have to be combined in order to give the best results. And while people consider the network as a useful instrument to increase citizen participation, further research needs to examine if they really do so in their actual political practices.

\subsection{New challenges}

Since the internet gained mass public in the early 1990s, new political forms of action emerged yet they were not as overwhelming as predicted and, contrary to the unbounded 
world announced, new borders emerged. If a real hype surrounded the concept(s) of e-democracy in its beginning, the internet is mostly used for other practices - leisure, communication, etc. - than political ones. Few people - including the respondents to our survey - use the internet in that way. Moreover, far from resolving traditional difficulties of democracy, the internet has contributed to create new ones. One might think about the increasing commercialisation of cyberspace, issues concerning the control of the internet or the fragmentation of public space.

The fast commercialisation of what used to be a military and scientific research network remains indeed controversial. Schiller (1997) denounced already in 1997 that network services tend to transform the internet more into a push medium, where the user plays a passive role, than a pull medium, where the user participates fully in the interaction. New political practices may have developed online, yet few citizens choose to engage in the democratic process through these (Coleman and Goetze, 2002; Vedel, 2007). Only a minority uses the internet in a political way. Influent online groups often tend to reflect existing offline lobbies. Media convergence on the internet pushes towards concentration, harming information freedom and pluralism.

The relation between the State and the internet is not less controversial. Though online exchanges are hard to supervise due to the anarchical and global nature of the internet, some researchers call for increased state regulation in order to guarantee public service on the network (Tsagarousianou et al., 1998). States continually try to control and supervise online activities by adapting their legislation. On the one side, they profit from ICT to promote more governmental transparency and openness. On the other side, public administrations use these tools to increase their efficiency to the point of developing into real infocraties (Zouridis, 1995). Yet, citizen control of State action also increases as individuals are able to inform and organise themselves online (Section 5).

Fragmentation of public space is another issue raised by the emerging cyberspace. Public space is considered as one of the cornerstones of modern democracies. Various opinions meet there, notably through the media. The use of ICT by citizens has contributed to the constitution of alternative public spaces, existing at the same time than those produced by the state and the mass media. Keane (2000) speaks about a multiplication of public spaces which can nevertheless be interconnected on the internet. However, a unifying 'common good' disappears as the public becomes fragmented in a multitude of groups, each one pursuing its own interest in spite of common goals.

\section{Web 2.0 and e-democracy}

This brief review of central themes surrounding e-democracy and the results of our survey underline that online political practices raise many issues and uncertainties. Yet e-democracy is still in its infancy. As shown in Section 3, there are several parallels between the concepts of e-democracy and the Web 2.0. Despite their limits - examined in Section 3 - we believe that some Web 2.0 applications may be useful to reinforce e-democracy. This paragraph considers specifically two axes pointed out by Vedel and underlined by our survey (Section 4.3):

- the search for political information

- political discussion. 
The authors believe that the use of Web 2.0 applications will not solve problems caused by false ideas and/or bad argumentation circulation on the internet. Only a better education of every citizen may help to resolve that kind of issues.

\subsection{Searching (political) information}

As shown in our survey, information search is a crucial issue for most Web users wishing to get politically active on the Net. Blogs will become - as they are already - more and more used to communicate on political subjects. A necessary filtering is necessary to select which blogs may be considered as relevant information sources. As for any internet site, the identification of the author(s) should be an important criteria. Two specific actors of political life could particularly see their importance as information sources being enhanced via internet blogging:

- professional political journalists who write mostly on blogs to avoid the constraints of their newspaper (in particular the fixed length of their papers)

- politicians who can detail their political vision more precisely than through an interview or a public speech.

However, the risk that those actors misuse their position as opinion leaders has to be taken into account. As they express themselves beyond the constraints of 'traditional' information selection mechanisms, the ability of citizens to distinguish between political communication and information becomes essential.

Likewise, social bookmarking applications may help citizens to access relevant political content. Some websites of 'traditional' medias such as the $\mathrm{BBC}^{6}$ use this principle to help their visitors to find the information they are searching for. Moreover, social bookmarking can ensure a given diversity of points of view when searching for information on a given subject. In fact, on very controversial subjects, it is highly probable that people defending opposite positions will use common keywords to tag documents containing their arguments. This may encourage internet users to compare arguments and proofs proposed by different points of views, enriching the political debate.

\subsection{Discussing political subjects}

Since most blogs allow Web surfers to add comments to the various entries, it is not unusual that a discussion is launched after information is published on a blog. In fact, any website allowing comments of internet users is a place where discussions may take place.

Wikis are also a kind of application that could be useful to discuss political subjects, in particular as support for already existing communities - e.g. a NGO. For more generic wikis, solutions to the critics made to Wikipedia - see Section 3.1 - have to be found. One often proposed remedy is to avoid the anonymity of the writer so that Web surfers might evaluate the authority of the authors.

As a consequence of online discussion, political networks tend to appear on the internet. Building those networks becomes an important issue since those connections allow users, not only to discuss subjects, but also to coordinate political actions. Social networking platforms are good mediators between Web surfers and, used on 
politically-oriented applications, it may help creating political networks. Yet, the risk that such political networks will strengthen the points of views of their members and radicalise their political visions has to be taken into account.

Some researchers have shown that it is possible to cluster internet users following the keywords they use to tag documents in social bookmarking applications (Paolillo and Penumarthy, 2007). If such technologies are used on politically-oriented applications, 'political clusters' may appear. In order to build communities of interests based on the content of the documents users consider as relevant, that kind of social browsing can be a solution (Francq, 2007). If this latest approach is not really labelled Web 2.0, it is still related to the idea of making something emerge from the behaviours of Web surfers. Every clustering application must be customized to find a balance between the homogeneity of each group - minimising the 'intra-distances' - and the difference between various groups - maximising the 'inter-distances'. In the context of automatically build political networks, these parameters must be chosen to ensure a certain diversity of points of views within a group.

The different potential applications of Web 2.0 applications in the context of e-democracy should be closely studied in future research projects. In particular, specific tools enabling political-oriented research should be developed and validated.

\section{Conclusions}

This paper examines how Web 2.0 applications find their utility in the larger context of e-democracy. A brief state-of-the-art shows the diversity of the $\operatorname{concept}(s)$ of e-democracy - notably by examining it through the three axes proposed by Vedel: information, discussion and decision-making - and the Web 2.0. In the context of e-democracy, the authors define the concept of Web 2.0 as a period characterized by a massive participation of internet users in the production of content on the Web. Tools such as blogs, wikis, social bookmarking and networking applications illustrate best this definition of the Web 2.0. Despite the legitimated critics, the authors argue that Web 2.0 applications may be useful for Web surfers to get more engaged in political issues. An analysis of an online survey answered by internet users highlights the main issues Web surfers are concerned about when considering online political activities. Information and discussion are important issues for Web users. Therefore, the authors consider that Web 2.0 applications might provide answers and solutions to important perceptions and expectations respondents expressed in our survey. Future works must examine these issues by combining offline and online methodologies.

Technologies alone are not a solution to ensure a higher citizen participation in the democratic process. Discourse surrounding e-democracy barely hides the eternal search for a political ideal (Vedel, 2003) that animates men at least since Plato. An ideal that may never be reached. As Vedel commets: "The idea of electronic democracy rests upon the implicit postulate that a large part of citizens wishes to implicate themself intensively in political life and that this implication passes by better information". The actual disinterest of many citizens concerning their political representation continues to be a major issue. Massive investment in public education is therefore a primary necessity in order to enhance essential knowledge and competence of citizens, enabling them to fully live their citizenship, in particular when information and communication technologies are involved. 


\section{References}

Abramson, J.B., Arterton, F.C. and Orren, G.R. (1988) The Electronic Commonwealth: The Impact of New Media Technologies on Democratic Politics, Basic Books, New York.

Barber, B.R. (2000) 'Which technology for which democracy? Which democracy for which technology?', International Journal of Communications Law and Policy, Vol. 6, pp.1-8.

Becker, T.L. and Slaton, C.D. (2000) The Future of Teledemocracy, Praeger, Westport.

Blood, R. (2002) The Weblog Handbook: Practical Advice on Creating and Maintaining Your Blog, Perseus Publishing, Cambridge.

Calenda, D. and Mosca, L. (2007) 'The political use of the internet: some insights from two surveys of Italian students', Information, Communication and Society, Vol. 10, pp.29-47.

Chen, M. and Singh, J.P. (2001) Computing and Using Reputations for Internet Ratings, ACM Press, Tampa, Florida, USA.

Coenen, T. (2006) Knowledge Sharing Over Social Networking Systems, PhD Thesis, Vrije Universiteit Brussel.

Coleman, S. and Goetze, J. (2002) Bowling Together: Online Public Engagement in Policy Deliberation, UK Hansard Society.

Constant, M. (2002) 'La démocratie locale en ligne au Québec', in Monière, D. (Ed.): Internet et la Démocratie, Monière et Wollank Editeurs, Canada, pp.126-139.

Corbineau, B. and Barchechath, E. (2003) 'The discourse on e-democracy: Where are we heading? in Cuningham, P.M. and Fateling, P. (Eds.): Building the Knowledge Economy. Issues, Applications; Case Studies, IOS Press, Oxford.

Edwards, A. (2004) Internet en democratische inter-mediaires: een nieuwe benadering van 'digitale democratie', Bestuurskunde, pp.154-162.

European Commission (2006) Eurobarometre Standard 66: L'opinion publique dans l'union europeenne.

Fallows, D. (2005) Search Engine Users. Internet Searchers are Confident, Satisfied and Trusting - but they are also Unaware and Nä̈ve, Pew Internet \& American Life Project, Available at: http://www.pewinternet.org/ppf/r/146/report_display.asp

Francq, P. (2007) The GALILEI Platform: Social Browsing to Build Communities of Interests and Share Relevant Information and Expertise, Idea Group Publishing, pp.319-342, Hershey, PA, USA.

Giles, J. (2005) 'Internet encyclopaedias go head to head', Nature, Vol. 438, pp.900-901.

Gillmor, D. (2006) We the Media: Grassroots Journalism by the People, For the People, O'Reilly, Available at: http://oreilly.com/catalog/wemedia/book/index.csp

Hacker, K.L. and Van Dijk, J. (2001) Digital Democracy: Issues of Theory and Practice, Sage Publications, Inc. Thousand Oaks, CA, USA.

Hagen, M. (1997) Elektronische Demokratie: Comput-ernetzwerke und politische Theorie in den USA, Lit-Verlagsgsellschaft, Hamburg.

Hoff, J., Tops, P. and Horrocks, I. (2000) Democratic Governance and New Technology: Technologically Mediated Innovations in Political Practice in Western Europe, Routledge, London.

Habermas, J. (1991) The Structural Transformation of the Public Sphere: An Inquiry into a Category of the Bourgeois Society, MIT Press, Cambridge.

Keane, J. (2000) 'Structural transformations of the public sphere', in Hacker, K.L. and Van Dijk, J. (Eds.): Digital Democracy: Issues of Theory and Practice, Sage Publications, Inc. Thousand Oaks, CA, USA, pp.70-90.

Keen, A. (2007) The Cult of the Amateur: How Today's Internet is Killing our Culture and Assaulting Our Economy, Nicholas Brealey Publishing, London. 
Lappin, T. (1995) 'Deja vu all over again', Wired, pp.175-177.

Levy, P. (2002) Cyberdemocratie: essai de philosophic poli-tique, Odile Jacob, Paris.

Loiseau, G. (2003) 'L'assujettissement des sites internet municipaux aux logiques sociétales', in Boure, R. and Loiseau, G. (Eds.): Démocratie locale et Internet, Sciences de la société, Toulouse, pp.86-105.

Maigret, E. (2000) 'La démocratie locale entre idéologies, identités et pratiques', in Wolton, D. (Ed.): www.démocratielocale.fr, HERMES: Cognition, Communication, Politique, pp.99-108.

McLuhan, H.M. (1962) The Gutenberg Galaxy: The Making of the Typographic Man, Routledge, London.

Paolillo, J.C. and Penumarthy, S. (2007) 'The Social Structure of Tagging Internet Video on Del.icio.us', System Sciences, 2007. HICSS 2007. 40th Annual Hawaii International Conference, pp.85-85.

Prevost, P. (2003) Projet développement des collectivités locales et régionales par les TI: rapport sur les différentes expériences structurantes de collectivités branchées dans le monde, CEFRIO, University de Sherbrooke, Available at: http://www.quebecinnovation2008.com/fr/publications.html

Rheingold, H. (2000) The Virtual Community: Homesteading on the Electronic Frontier, 2nd ed., MIT Press, Cambridge.

Sassi, S. (2000) 'The Controversies of the Internet and the Revitalization of Local Political Life', in Hacker, K.L. and Van Dijk, J. (Eds.): Digital Democracy: Issues of Theory and Practice, Sage Publications, London, pp.90-104

Schiff, S. (2006) 'Know it all: can wikipedia conquer expertise?', The New Yorker, July 2006, Retrieved from http://www.newyorker.com/archive/2006/07/31/060731fa_fact

Schiller, D. (1997) Les marchands à l'assaut d'internet, Le monde diplomatique, pp.24-25, March.

Sclove, R. (2003) Choix technologiques, choix de société, Editions Descartes \& Cie, Paris.

Shannon, M.M. (2007) 'Shaking hands, kissing babies, and blogging', Communications of the $A C M$, Vol. 50, pp.21-24.

Tsagarousianou, R., Tambini, D. and Bryan, C. (1998) Cyberdemocracy: Technology, Cities and Civic Networks, Routledge, London.

van de Donk, W., Snellen, I.T.M. and Tops, P.W. (1995) Orwell in Athens: A Perspective on Informatization and Democracy, IOS Press, Amsterdam.

Vedel, T. (2003) L'idee de democratie electronique: Origines, visions, questions, Le desenchantement democratique, La Tour d'Aigues, pp.243-266.

Vedel, T. (2007) 'Les usages politiques d'Internet', in Masquet, B. (Ed.): La démocratie électrionique, Ed. La Documentation française, Paris, pp.15-26.

Waters, N.L. (2007) 'Why You Can't Cite Wikipedia in My Class', Communications of the ACM, Vol. 50, pp.15-17.

Wiener, N. (1965) Cybernetics: Or Control and Communication in the Animal and the Machine, Mit Pr, MIT Press, Cambridge.

Wolton, D. (2000) 'www.démocratielocale.fr', Hermes: Cognition, Communication, Politique, pp.85-384.

Yildiz, H. (2002) 'Internet: un nouvel outil de communication multidimensionnel', in Serfaty, V. (Ed.): L'Internet en politique des Etats-Unis à l'Europe, Presses Universitaires de Strasbourg, Strasbourg, pp.275-290

Zouridis, S. (1995) Information Technology, Openness of Government and Democracy, IOS Press edition, Amsterdam, The Netherlands, pp.186-194. 


\section{Notes}

${ }^{1}$ However, the concept of democracy in Antique Athens was quite different from the contemporary political concept. A large part of the population was indeed excluded from citizenship (e.g. woman and foreigners) as only male adults (aged 18 and higher), born in Athens and having completed their military training were allowed to vote.

${ }^{2}$ Technorati (www.technorati.com) is the most known search engine for blogs.

${ }^{3}$ Wikipedia project: http://www.wikipedia.org

${ }^{4}$ The questionnaire was available in four languages: French, German, English and Dutch.

${ }^{5} \mathrm{We}$ suppose that engaged people participate in offline political activities.

${ }^{6} \mathrm{http}: / /$ www.bbc.co.uk 